http://jmscr.igmpublication.org/home/ ISSN (e)-2347-176x ISSN (p) 2455-0450

crossref DOI: https://dx.doi.org/10.18535/jmscr/v8i1.59

\title{
Correlation of Novel Risk Factors with Syntax Score in Young and Elderly Males with Coronary Artery Disease
}

\author{
Authors \\ Ushnish Chakrabarty ${ }^{1}$, Swarnendu Datta ${ }^{1}$, Plaban Mukherjee ${ }^{1}$ \\ Department of Cardio Thoracic \& Vascular Surgery, Medical College and Hospital Kolkata \\ Kolkata, India
}

\begin{abstract}
Worldwide, Coronary Artery Disease (CAD) is one of the leading causes of death. Patients from the Indian subcontinent present relatively early and may have more extensive CAD. Various Conventional and Novel risk factors for CAD have been studied. In this study apart from the Conventional risk factors, we assessed the Novel risk factors like Hyperhomocysteinaemia, Lipoprotein a (Lpa), Apolipoprotein B (Apo B), Apolipoprotein $A_{1}$ (Apo $A_{1}$ ) and Apolipoprotein B/A ratio in both the Elderly (>45 years) \& Young ( $\leq 45$ years) groups and correlated their values with the SYNTAX Score to find out if there was any correlation between the levels of the Novel risk factors and the SYNTAX score. We found that the Homocysteine levels in young patients correlated linearly with their respective Syntax scores with a highly significant ' $p$ ' value of 0.001355. This was however not so in the elderly group. It was also derived from this study that serum Homocysteine levels in young coronary artery disease patients are $83.33 \%$ sensitive, $91.67 \%$ specific and $86.67 \%$ accurate in predicting complexity of coronary lesions and thus the aggressiveness of the disease in terms of their Syntax scores.
\end{abstract}

\section{Introduction}

The spectrum of coronary artery disease (CAD) in India reveals, that not only is CAD more diffuse \& aggressive, but affects people at an earlier age $^{1,2}$. We have found that one in five patients who are admitted for CABG in our unit are less than 45 years of age. Apart from the Conventional risk factors, we assessed the Novel risk factors like Hyperhomocysteinaemia, Lipoprotein a (Lpa), Apolipoprotein B (Apo B), Apolipoprotein $\mathrm{A}_{1}$ (Apo $\mathrm{A}_{1}$ ) and Apolipoprotein $\mathrm{B} / \mathrm{A}$ ratio in both the Elderly \& Young group and correlated their values with the SYNTAX Score for all our patients in the study groups to find out if there was any correlation between the levels of the Novel risk factors and the SYNTAX score.

\section{Objective}

To find out if there is any correlation between conventional and/or novel risk factors with the severity of Coronary Artery Disease as defined by SYNTAX score in young ( $\leq 45$ years) and elderly ( $>45$ years) coronary artery disease patients.

\section{Methods and Materials}

This prospective analytical observational study was carried out between 01.02.2014 to 31.01.2016 in the Department of CTVS Medical College Kolkata. 


\section{Patient Population}

Patients admitted in CTVS department for CABG. They were divided into 2 groups:
1) Young $\leq 45$ years
2) Elderly $>45$ years

During the study period, since there were no female patients below the age of 45 years admitted for $\mathrm{CABG}$, we did not take female patients in our study.

We did not include patients who underwent:
1) Emergency $\mathrm{CABG}$
2) Had previous PCI
3) Associated valvular heart disease and
4) With mechanical complications of CAD

So the number of patients in the study was 132 patients. This sample size was more than the required sample size of 98 (considering a margin of error of $5 \%$, a confidence level of $95 \%$ and a response distribution of $50 \%$ ).

Matching of the young and elderly groups was done by using a baseline criteria of BMI $\geq 23$ (overweight, at risk of obesity, obese- I, obeseII) ${ }^{3}$.

Actual sample size after applying Matching criteria was 99.

Group A- young patients young ( $\leq 45$ years)

Group B- elderly ( $>45$ years)

Evaluation of Risk Factors:

The following CAD risk factors were evaluated in every patient:-

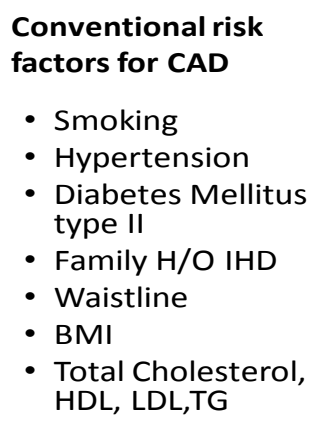
HDL, LDL,TG

SYNTAX score was calculated in each case from the preoperative Coronary Angiogram using online SYNTAX Score calculator version 2.11.

\section{Results}

Conventional risk factor results in two groups (Table 1)

\begin{tabular}{|l|c|c|}
\hline & $\begin{array}{c}\text { Group A - } \leq 45 \\
\text { Years }(\mathrm{n}=30)\end{array}$ & $\begin{array}{c}\text { Group B - >45 } \\
\text { Years (n=69) }\end{array}$ \\
\hline Smokers & $22(73 \%)$ & $48(70 \%)$ \\
\hline Hypertensives & $18(60 \%)$ & $43(62 \%)$ \\
\hline Diabetics & $11(37 \%)$ & $23(33 \%)$ \\
\hline $\begin{array}{l}\text { Family History of } \\
\text { IHD }\end{array}$ & $13(42 \%)$ & $29(42 \%)$ \\
\hline Waistline $>90 \mathrm{cms}$ & $14(46 \%)$ & $33(48 \%)$ \\
\hline BMI>25 & $13(42 \%)$ & $17(25 \%)$ \\
\hline History of AMI & $17(58 \%)$ & $19(28 \%)$ \\
\hline HDL <40 mg/dl & $22(73 \%)$ & $26(38 \%)$ \\
\hline
\end{tabular}

To evaluate whether HDL level variance in the two groups is statistically significant, we used the "Two Sample T-test assuming unequal variance". The p-value was $<0.00254$, making the result highly significant.

Novel risk factor results in two groups (Table 2)

\begin{tabular}{|l|c|c|}
\hline & $\begin{array}{c}\text { Group A - } \leq 45 \\
\text { Years }(\mathrm{n}=30)\end{array}$ & $\begin{array}{c}\text { Group B - }>45 \\
\text { Years }(\mathrm{n}=69)\end{array}$ \\
\hline $\begin{array}{l}\text { Homocysteine } \\
\geq 30 \mu \mathrm{mol} / \mathrm{L}\end{array}$ & $16(53 \%)$ & $12(17 \%)$ \\
\hline $\mathrm{Lp}(\mathrm{a}) \geq 30 \mathrm{mg} / \mathrm{dl}$ & $19(63 \%)$ & $49(71 \%)$ \\
\hline Apo B $>140 \mathrm{mg} / \mathrm{dl}$ & $7(23 \%)$ & $7(10 \%)$ \\
\hline Apo $\mathrm{A}_{1}<110 \mathrm{mg} / \mathrm{dl}$ & $3(10 \%)$ & $8(12 \%)$ \\
\hline Apo B: $\mathrm{A}_{1}$ ratio $>1$ & $9(30 \%)$ & $14(20 \%)$ \\
\hline
\end{tabular}

To evaluate whether this Homocysteine level variance was statistically significant in the two groups, we used used the "Two Sample T-test assuming unequal variance". The p-value was $<0.0485$, making the result significant.

SYNTAX scores in the two groups (Table 3)

\begin{tabular}{|l|c|c|}
\hline & $\begin{array}{c}\text { Group A - } \leq 45 \\
\text { Years }(\mathrm{n}=30)\end{array}$ & $\begin{array}{c}\text { Group B - >45 } \\
\text { Years }(\mathrm{n}=69)\end{array}$ \\
\hline Mean Syntax score & $27.27 \pm 8.41$ & $24.32 \pm 6.22$ \\
\hline $\begin{array}{l}\text { Low Syntax score } \\
(0-22)\end{array}$ & $12(40 \%)$ & $29(42 \%)$ \\
\hline $\begin{array}{l}\text { Intermediate Syntax } \\
\text { scor (23-33) }\end{array}$ & $8(27 \%)$ & $34(50 \%)$ \\
\hline $\begin{array}{l}\text { High Syntax score } \\
(>33)\end{array}$ & $10(33 \%)$ & $6(8 \%)$ \\
\hline
\end{tabular}

In order to find out whether there is any relationship between serum Homocysteine and SYNTAX scores in the young and elderly population, regression analysis was done. The 
regression "p-value" was found to be statistically highly significant in the young group only (0.00135) as shown in table 4 and corroborated by a steep slope of the scatter plot in Figure 1. However, it was not so in the elderly as in Figure 2 .

Table-4: Regression analysis showing a significant 'p' value, indicating a linear relationship between Serum Homocysteine \& SYNTAX score in YOUNG population ie. group A.
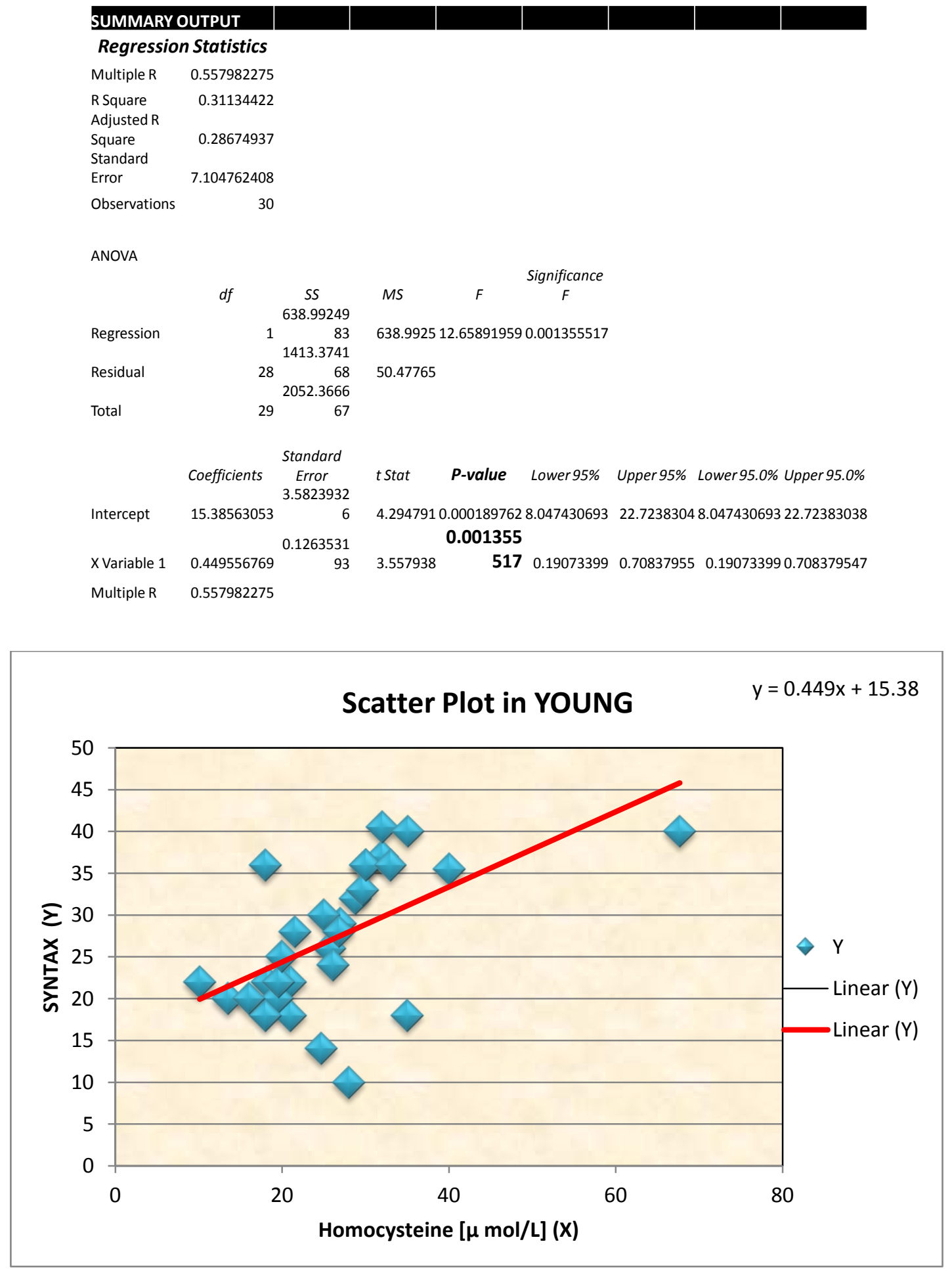

Figure-1: Scatter plot relating serum Homocysteine [x-axis] with SYNTAX score [y-axis] in YOUNG [group A]. Each of the 30 young patients are represented by a blue dot on the chart. The statistically significant (' $p$ value'- $\mathbf{0 . 0 0 1 3 5 5 5 1 7 ) ~ l i n e a r ~ r e l a t i o n s h i p ~ b e t w e e n ~ t h e ~ t w o ~ v a r i a b l e s ~ i s ~ r e p r e s e n t e d ~ b y ~ t h e ~ r e d ~}$ trend-line which has a steep slope (equation for this trend line: $\mathbf{y}=\mathbf{0 . 4 4 9} x+\mathbf{1 5 . 3 8}$ ). 


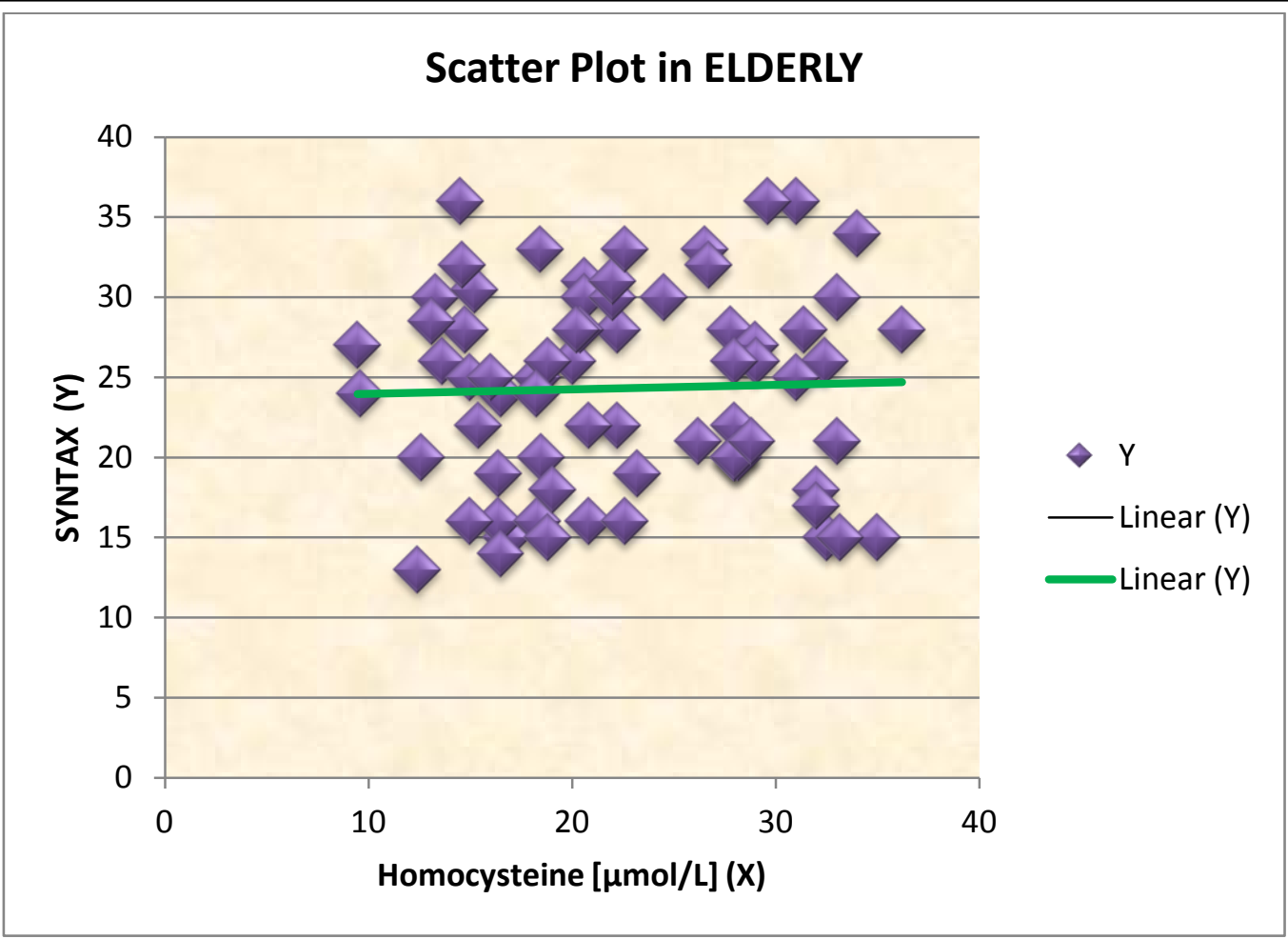

Figure- 2: Scatter plot relating serum Homocysteine [x-axis] with SYNTAX score [y-axis] in ELDERLY. Each of the 69 elderly patients are represented by a purple dot on the chart. The resultant trend line in green has a flat slope showing absence of any linear relationship between Homocysteine \& SYNTAX score in ELDERLY [group B].

From this we conclude that High Homocysteine value can predict HIGH Syntax score in young population but no similar relationship could be derived in the elderly.

In order to find out how robust an investigation serum Homocysteine is, in predicting complexity of coronary artery lesions in terms of SYNTAX scores in YOUNG population, the following groups were defined:

True Positive: Those who have raised Homocyteine levels \& Intermediate/High SYNTAX scores.
False Positive: Those who have raised serum Homocyteine levels \& Low SYNTAX scores.

True Negative: Those who have normal serum Homocyteine levels \& Low SYNTAX scores.

False Negative: Those who have normal Homocyteine levels \& Intermediate/High SYNTAX scores.

These values were filled in a $2 \times 2$ contingency table \& represented [Table-5] below:

Table - 5: True positive, False positive, True negative \& False negative groups; when Serum Homocysteine is used to predict SYNTAX scores in YOUNG population [Group A]

\begin{tabular}{|l|c|c|}
\hline YOUNG & Homocysteine $\geq 30 \mu \mathrm{mol} / \mathrm{L}$ & Homocysteine $<30 \mu \mathrm{mol} / \mathrm{L}$ \\
CAD PATIENTS & TRUE POSITIVE & FALSE NEGATIVE [FN] \\
\hline Syntax $\geq 23$ & {$[\mathrm{TP}]$} & $\mathrm{n}=3$ \\
& $\mathrm{n}=15$ & \\
\hline Syntax $<23$ & FALSE POSITIVE & TRUE NEGATIVE [TN] \\
& {$[\mathrm{FP}]$} & $\mathrm{n}=11$ \\
& $\mathrm{n}=1$ & \\
\hline
\end{tabular}


The following Table (Table 6) shows how good Serum Homocysteine is as a test to predict complexity of coronary artery lesions [as SYNTAX scores], in YOUNG population.

Table - 6: Sensitivity, Specificity, Positive/ Negative Predictive values \& Diagnostic accuracy of serum Homocysteine as a test to predict coronary artery lesion complexity in terms of SYNTAX scores in YOUNG population [group A].

\begin{tabular}{|l|c|l|}
\hline SENSITIVITY & {$[\mathrm{TP} /(\mathrm{TP}+\mathrm{FN})]$ X $100 \%$} & $83.33 \%$ \\
\hline SPECIFICITY & {$[\mathrm{TN} /(\mathrm{TN}+\mathrm{FP})]$ X 100\% } & $91.67 \%$ \\
\hline POSITIVE PREDICTIVE VALUE & {$[\mathrm{TP} /(\mathrm{TP}+\mathrm{FP})]$ X $100 \%$} & $93.75 \%$ \\
\hline NEGATIVE PREDICTIVE VALUE & {$[\mathrm{TN} /(\mathrm{FN}+\mathrm{TN})] \mathrm{X} \mathrm{100 \%}$} & $78.57 \%$ \\
\hline DIAGNOSTIC ACCURACY & {$[(\mathrm{TP}+\mathrm{TN}) /(\mathrm{TP}+\mathrm{FP}+\mathrm{FN}+\mathrm{TN})] \times 100 \%$} & $86.67 \%$ \\
\hline
\end{tabular}

\section{Discussion}

In this study, we evaluated the various risk factors in young ( $\leq 45$ Years) and elderly ( $>45$ years) Coronary Artery Disease (CAD) patients and tried to find out if there was any direct correlation between the risk factors and the severity or extent of CAD as determined by Syntax score.

Syntax Scores have been classified into 3 groups High ( $\geq 33$ ), Intermediate (22-32) and Low (0-22). Higher Syntax Scores indicate more complex disease and represent a bigger theraputic challenge.

In this study we did find a strong correlation between levels of Serum Homocysteine and complexity of coronary artery disease as determined by syntax scores in Young $(\leq 45$ Years) CAD patients. This was not however true for the Elderly ( $>45$ years).

In fact using the scatter plot and the resultant “ trend line", we noticed a very steep slope of the trend line, indicating that, the higher the Serum Homocysteine level, the more was the Syntax score.

Boushey et al ${ }^{4}$ reported a metaanalysis of 27 observational studies including about 4000 patients. A raised Homocysteine level (defined as above the 90th or 95th percentile of controls) was associated with an increased risk of fatal and nonfatal atherosclerotic vascular disease in the coronary artery (odds ratio 1.7 ; 95\% CI 1.5-1.9). However no objective correlation was made to evaluate Homocysteine levels with the complexity and severity of atherosclerotic CAD.
In this study the Homocysteine levels in young patients correlated linearly with their respactive Syntax scores with a highly significant ' $p$ ' valueof 0.001355 .

It was also derived from this study that serum Homocysteine levels in young coronary artery disease patients are $83.33 \%$ sensitive, $91.67 \%$ specific and $86.67 \%$ accurate in predicting complexity of coronary lesions and thus the aggressiveness of the disease in terms of their Syntax scores.

\section{Conclusion}

We can conclude that in the Eastern Indian population who suffer from coronary artery disease:

a) A significantly higher number of young patients with CAD have greater serum Homocysteine levels compared to elderly.

b) Serum Homocysteine levels correlate linearly with the respective Syntax scores in young patients and higher Homocysteine levels are predictive of more complex disease with higher Syntax scores.

c) Greater number of younger patients tend to have low HDL levels compared to elderly but no correlation could be found between low HDL levels and respective Syntax Scores.

\section{References}

1. Vardan S, Mookherjee S, Vardan S, Sinha AK. Special Features of coronary heart 
disease in people of the Indian subcontinent. Indian Heart J 1995;47:399-407.

2. Klein LW, Agarwal JB, Herlich MB. Prognosis of symptomatic coronary artery disease in young adults aged 40 years or less. Am J Cardiol 1987; 60:1267-72.

3. The Asia Pacific perspective. Redefining obesity and its treatment. World Health Organization. International association for the study of obesity and International obesity task force. International Diabetes Institute, Melbourne: World Health Organization, Western Pacific Region; 2000.

4. Boushey CJ, Bareford SAA, Omenn GS, Motulsky AG. A quantitative assessment of plasma homocysteine as a risk factor for vascular disease: probable benefits of increasing folic acid intake. J Am Med Asso 1995;274:1049-57. 